\title{
Верификация системного подхода выполнения симультанных операций на органах брюшной полости и брюшной стенке у болыных с вентральной грыжей
}

\begin{abstract}
Цель работы: улучшение качества лечения больных с вентральной грыжей (ВГ) путем снижения частоты и тяжести осложнений после симультанных и реконструктивно-восстановительных операций на органах брюшной полости и брюшной стенке.

Материалы и методы. В основу исследования включены результаты лечения 197 больных с симультанной патологией органов брюшной полости и брюшной стенке, поступивших в хирургическое отделение 1-й клиники Самаркандского государственного медицинского института.

Результаты исследований и их обсуждение. У 197 пациентов после операции сохранялась нормальная функция ЖКТ, лишь у 4 больных (3 и 1 пациент в группах исследования) отмечался парез кишечника, купированный медикаментозно. Абдоминальные осложнения отмечены у 10 (5,1%) больных. В раннем послеоперационном периоде абдоминальные осложнения после симультанных операций можно разделить на два: осложнения со стороны основного этапа операции и осложнения со стороны симультанного этапа операции. Со стороны основного этапа операции у 5 (2,5 \%) больных (3 в группе сравнения и 2 в основной группе) после герниоаллопластики наблюдали парез кишечника и 1 (0,5%) больного из группы сравнения также после герниоаллопластики отмечено задержку мочи. У 2 (2,1%) больных из группы сравнения причиной пареза кишечника и задержки мочи было повышенное внутрибрюшное давление.

Использование усовершенствованной модифицированной шкалы прогнозирования периоперационных осложнений позволило достоверно улучшить качество предоперационной подготовки больных с ВГ и сопутствующими симультанными хирургическими заболеваниями органов брюшной полости, достигнуть улучшения состояния пациента в более ранние сроки и соответственно сократить частоту послеоперационных внеабдоминальных осложнений с 10,7 до 2,8 \%.
\end{abstract}

Ключевые слова: вентральная грыжа; брюшная полость; симультанная патология; симультанные операции; качество жизни больных.

Постановка проблемы и анализ последних исследований и публикаций. Анестезиологу и хирургу важно знать, перенесет ли данный больной операцию вообще, какие осложнения ему наиболее угрожают и что надо сделать, чтобы уменьшить их вероятность [1, 3]. Несмотря на разнообразие шкал и классификаций операционно-анестезиологического риска и исходного состояния больного, вероятность развития периоперационных осложнений остается неизвестной $[1,4]$.

Система АРАСНЕ была раскритикована, так как неизмеренные величины по умолчанию принимались равными нулю, т. е. считались нормальными, а количество переменных было избыточным и могло привести к ошибкам ввиду того, что некоторые параметры могли в одиночку коррелировать с вероятностью летального исхода [2].

Анализ научно-медицинской и патентной документации свидетельствует о том, что в доступной нам литературе отсутствует определение показаний к использованию того или иного способа операции с учетом различных факторов, влияющих на результаты лечения.

Разработанные шкалы оценки факторов, влияющих на выбор операции, не всегда позволяют выбрать оптимальный способ операции с учетом индивидуальных особенностей организма и улучшить результаты лечения.

Цель работы: улучшение качества лечения больных с вентральной грыжей путем снижения частоты и тяжести осложнений после симультанных и реконструктивно-восстановительных операций на органах брюшной полости и брюшной стенке.

Материалы и методы. В основу исследования включены результаты лечения 197 больных с симультанной патологией органов брюшной полости и брюшной стенки, поступивших в хирургическое отделение 1-й клиники Самаркандского государственного медицинского института. Оценка степени операционно-анестезиологического риска у обследованных больных нами проводилась согласно классификации ASA (Американского общества анестезиологов). Из числа обследованных больных 55 (27,9 \%) пациентов имели сопутствующие патологии и в ходе распределения, с учетом классификации ASA, относились ко II классу, из них 3 больных относились к III классу, остальные - 142 (72,1 \%) больные относились к I функциональному классу (табл. 1). 
Таблица 1. Степень операционно-анестезиологического риска

\begin{tabular}{|c|c|c|c|c|c|c|}
\hline \multirow{3}{*}{ Класс ASA } & \multicolumn{4}{|c|}{ Исследуемые группы } & \multirow{2}{*}{\multicolumn{2}{|c|}{ Всего }} \\
\hline & \multicolumn{2}{|c|}{ основная группа } & \multicolumn{2}{|c|}{ группа сравнения } & & \\
\hline & абс. & $\%$ & абс. & $\%$ & абс. & $\%$ \\
\hline $\mathrm{I}$ & 72 & 69,2 & 70 & 75,3 & 142 & 72,1 \\
\hline II & 30 & 28,8 & 22 & 23,6 & 52 & 26,4 \\
\hline III & 2 & 1,9 & 1 & 1,1 & 3 & 1,5 \\
\hline IV & - & - & - & - & - & - \\
\hline $\mathrm{V}$ & - & - & - & - & - & - \\
\hline Всего & 104 & 100 & 93 & 100 & 197 & 100 \\
\hline
\end{tabular}

Несмотря на оценивание физического статуса больных по классификации ASA, у больных в группе сравнения встречались периоперационные осложнения со стороны сердечно-сосудистой $(13,9 \%)$ и респираторной системы $(5,4 \%)$.

В основной группе физический статус больных оценивался также по классификации ASA. B отличии от группы сравнения у больных в основной группе учитывали не только соматическую патологию, но и ее клинико-лабораторные признаки. Каждый признак оценивали как фактор риска развития периоперационных осложнений.
В связи с чем, на основании обзора литературы и собственного опыта нами разработана программа балльной оценки прогнозирования развития периоперационных осложнений у больных с планированными симультанными вмешательствами на органах брюшной полости и брюшной стенке (табл. 2). Таким образом, на основании комплексного обследования нами было выделено группы больных, которые требовали направленных мер по коррекции системной дисфункции. Учитывали, что симультанные вмешательства не выполняются у пациентов со стенокардией напряжения

Таблица 2. Бальная система прогнозирования развития периоперационных осложнений у больных с планированными симультанными вмешательствами на органах брюшной полости и брюшной стенке

\begin{tabular}{|c|c|c|c|}
\hline № & Факторы риска & Характеристика факторов & Баллы \\
\hline 1 & 2 & 3 & 4 \\
\hline 1 & Возраст & $\begin{array}{l}\text { до } 40 \text { лет } \\
41-60 \text { лет } \\
61-70 \text { лет } \\
\text { свыше } 71 \text { года }\end{array}$ & $\begin{array}{l}0 \\
1 \\
2 \\
3\end{array}$ \\
\hline 2 & Вес (индекс массы тела) & $\begin{array}{l}\text { Норма } \\
\text { Ожирение I-II степени } \\
\text { Ожирение III степени }\end{array}$ & $\begin{array}{l}0 \\
1 \\
2\end{array}$ \\
\hline 3 & $\begin{array}{l}\text { Оценивание физического статуса } \\
\text { больных по классификации ASA }\end{array}$ & $\begin{array}{l}\text { I } \\
\text { II } \\
\text { III }\end{array}$ & $\begin{array}{l}0 \\
1 \\
2\end{array}$ \\
\hline 4 & $\begin{array}{l}\text { Функциональное состояние } \\
\text { дыхательной системы }\end{array}$ & $\begin{array}{l}\text { Нарушений нет } \\
\text { Злоупотребляет курением } \\
\text { Периодическое затруднение дыхания } \\
\text { Хроническая дыхательная недостаточность }\end{array}$ & $\begin{array}{l}0 \\
1 \\
2 \\
3\end{array}$ \\
\hline 5 & $\begin{array}{l}\text { Функциональное состояние } \\
\text { сердечно-сосудистой системы }\end{array}$ & $\begin{array}{l}\text { ЭКГ в норме } \\
\text { Артериальная гипертензия } \\
\text { Гипоксия миокарда } \\
\text { Аритмия } \\
\text { ФВ левого желудочка ниже } 55 \text { \% }\end{array}$ & $\begin{array}{l}0 \\
1 \\
2 \\
3 \\
4\end{array}$ \\
\hline
\end{tabular}


Прод. табл. 2

\begin{tabular}{||l|l|l|c||}
\hline \hline 1 & \multicolumn{1}{|c|}{2} & \multicolumn{1}{|c||}{3} & 4 \\
\hline \multirow{2}{*}{6} & Сахарный диабет & Нет & 0 \\
& & II тип & 1 \\
& & I тип & 2 \\
\hline 7 & Хроническая венозная & Отсутствует & 0 \\
& недостаточность & I & 1 \\
& & II & 2 \\
\hline \multirow{2}{*}{8} & РІІ & 3 \\
& Размеры грыжевых ворот & до 5 см & 0 \\
& & 6-10 см & 1 \\
& & б1-15 см & 3 \\
\hline 9 & более 15 см & 0 \\
& Показатели свертывающей системы & Норма & 4 \\
\hline \hline
\end{tabular}

3-4 ст., сердечной недостаточностью 3-4 ст., и такие пациенты не были включены в анализ.

На основании этого мы разработали алгоритм ведения пациентов с высоким риском развития периоперационных осложнений. К группе высокого риска отнесли пациентов с суммой баллов более 20, к группе среднего риска - от 11 до 19 баллов, к группе низкого риска - от 0 до 10 баллов. Показанием к операции считали больных набравших до 10 баллов. Этим больным после стандартной предоперационной подготовки проводили симультанные операции. Больным, набравшим баллы более 15, продолжали предоперационную подготовку до тех пор, пока набранные баллы не снижались менее 15,5 (4,8 \%), больным из основной группы, набравшим более 15 баллов, потребовалось продолжение предоперационной подготовки.

На предоперационном этапе тактику обследования и ведения хирургических больных можно считать успешной, если она позволяет не только выявить, но и снизить периоперационный (ранний) риск развития сердечно-сосудистых и респираторных осложнений. Таким образом, информация, получаемая с помощью различных методов, согласно данному алгоритму, имеет как диагностическую, так и прогностическую ценность.

Результаты исследований и их обсуждение. Совершенствование выбора тактики хирургического лечения вентральных грыж сопутствующей хирургической патологией органов брюшной полости, техники выполнения хирургического вмешательства и другие новшества, разработанные и внедренные в рамках данного исследования, не могли не отразиться на непосредственных результатах ведения этой категории пациентов. У
197 пациентов после операции сохранялась нормальная функция ЖКТ, лишь у 4 больных (3 и 1 пациент в группах исследования) отмечался парез кишечника, купированный медикаментозно. Абдоминальные осложнения отмечены у 10 $(5,1 \%)$ больных. В раннем послеоперационном периоде абдоминальные осложнения после симультанных операций можно разделить на два: осложнения со стороны основного этапа операции и осложнения со стороны симультанного этапа операции. Со стороны основного этапа операции у 5 (2,5 \%) больных (3 в группе сравнения и 2 в основной группе) после герниоаллопластики наблюдали парез кишечника и 1 (0,5 \%) больного из группы сравнения также после герниоаллопластики отмечено задержку мочи. У 2 (2,1 \%) больных из группы сравнения причиной пареза кишечника и задержки мочи было повышенное внутрибрюшное давление.

Со стороны симультанного этапа операции у 4 (2,0 \%) больных отмечены абдоминальные осложнения. Из них у 3 (2 и 1) после холецистэктомии отмечено наружное желчеистечение по страховочному дренажу. Желчеистечение самостоятельно остановилось на 7-15 сутки после операции. У 1 (1,1\%) больного из группы сравнения отмечено нагноение остаточной полости после эхинококкэктомии из печени, которое проявилось повышением температуры тела и гнойными выделениями по страховочному дренажу, который находится в остаточной полости.

В раннем послеоперационном периоде внеабдоминальные осложнения наблюдались в 13 (6,6 \%) больных в обеих исследуемых группах. Бронхолегочные осложнения отмечены в 3 $(3,2$ \%) случаях в группе сравнения и у 2 (1,9 \%) пациентов в основной группе. Сердечно-сосуди- 
стые осложнения наблюдались у 5 (5,4 \%) пациентов группы сравнения и 1 (0,96 \%) больного в основной группе. Развитие САК (компартмент) произошло у 2 (2,1%) пациентов группы сравнения.

Среди раневых осложнений послеоперационные гематомы отмечены в 3 (3,2 \%) и 1 (0,96 \%) случаев соответственно, серомы у 8 (8,6 \%) и 3 (2,9 \%) больных, лимфорея у 5 (5,4 \%) и 2 (1,9 \%), нагноение раны у 2 (2,1 \%) больных в группе сравнения и некроз края кожного лоскута в 3 (3,2 \%) и 1 (0,9 \%) случаях (табл. 3). Следует отметить, что в среднем на одного больного группе сравнения приходилось 2-3 осложнения в виде сочетания бронхо-легочных или (и) сердечно-сосудистых с раневыми осложнениями. В целом в группе сравнения было 17 (18,3 \% из 93) больных с различными осложнениями. В основной группе было 9 (8,6 \% из 104) больных с различными осложнениями. По сравнительному признаку по количеству осложнений получено достоверное улучшение в основной группе.

Выводы. Факторами риска развития периоперационных осложнений после симультанных и реконструктивно-восстановительных операций на органах брюшной полости и брюшной стенке были клинико-лабораторные признаки сопутствующих соматических заболеваний.

Таблица 3. Осложнения в раннем послеоперационном периоде

\begin{tabular}{|c|c|c|c|c|c|c|}
\hline \multirow{2}{*}{ Осложнения } & \multicolumn{2}{|c|}{ Группа сравнения (n=93) } & \multicolumn{2}{|c|}{ Основная группа (n=104) } & \multicolumn{2}{|c|}{ Итого $(\mathrm{n}=197)$} \\
\hline & абс. & $\%$ & абс. & $\%$ & абс. & $\%$ \\
\hline \multicolumn{7}{|c|}{ Абдоминальные осложнения } \\
\hline Парез кишечника & 3 & 3,2 & 2 & 1,9 & 5 & 2,5 \\
\hline Задержка мочи & 1 & 1,1 & & & 1 & 0,5 \\
\hline Желчеистечение & 2 & 2,1 & 1 & 0,9 & 3 & 1,5 \\
\hline Нагноение остаточной полости & 1 & 1,1 & & & 1 & 0,5 \\
\hline \multicolumn{7}{|c|}{ Внеабдоминальные осложнения } \\
\hline Бронхолегочные осложнения & 3 & 3,2 & 2 & 1,9 & 5 & 2,5 \\
\hline Сердечно-сосудистые осложнения & 5 & 5,4 & 1 & 0,9 & 6 & 3,0 \\
\hline Компартмент-синдром & 2 & 2,1 & & & 2 & 1,0 \\
\hline \multicolumn{7}{|c|}{ Раневые осложнения } \\
\hline Гематома & 3 & 3,2 & 1 & 0,9 & 4 & 2,0 \\
\hline Серома & 8 & 8,6 & 3 & 2,9 & 11 & 5,6 \\
\hline Лимфорея & 5 & 5,4 & 2 & 1,9 & 7 & 3,5 \\
\hline Нагноение раны & 2 & 2,1 & & & 2 & 1,0 \\
\hline Некроз края кожного лоскута & 3 & 3,2 & 1 & 0,9 & 4 & 2,0 \\
\hline
\end{tabular}

Использование усовершенствованной модифицированной шкалы прогнозирования периоперационных осложнений позволило достоверно улучшить качество предоперационной подготовки больных с ВГ и сопутствующими симультанными хирургическими заболеваниями органов брюшной полости, достигнуть улучшения состояния пациента в более ранние сроки и соответственно сократить частоту послеоперационных внеабдоминальных осложнений с 10,7 до 2,8 \%.
Применение предложенного алгоритма с учетом усовершенствованных тактико-технических аспектов хирургического лечения ВГ с симультанной хирургической патологией органов брюшной полости позволило снизить общую частоту послеоперационных осложнений с 18,3 до 8,6 \% $(\mathrm{p}=0,045)$, в том числе раневых с 22,5 до 6,6 \% и внеабдоминальных с 10,7 до 2,8 \%, а также достоверно сократить продолжительность оперативного лечения и периоды реабилитации после различных вариантов герниопластики. 


\section{СПИСОК ЛИТЕРАТУРЫ}

1. Садчиков Д. В. Периоперационные осложнения у пациентов высокого анестезиолого-операционного риска (обзор, ч. ІІ) / Д. В. Садчиков, М. В. Пригородов, Т. С. Вартанян // Саратовский научно-медицинский журнал. - 2012. - Т. 8. - № 1. 2. Профилактика послеоперационных вентральных грыж: современное состояние проблемы / Суковатых Б. С. [и др.] // Хирургия. Журнал им. Н. И. Пирогова. - 2016. - № 3. - С. 7680. doi: 10.17116/hirurgia2016376-80

\section{REFERENCES}

1. Sadchikov, D.V., Prigorodov,, M.V.,\& Vartanyan, T.S. (2012). Perioperatsionnye oslozhneniya u patsiyentov vysokogo anesteziologo-operatsionnogo riska (obzor, ch. II) [Perioperative complications in patients with high anesthetic and operational risk (review, part II)]. Saratovskiy nauch.-med. zhurn. - Saratov Scientific and Medical Journal, 8 [in Russian].

2. Sukhovatykh, B.S. (2016). Profilaktika posleoperatsionnykh ventralnykh gryzh: sovremennoye sostoyaniye problem [Prevention of incisional ventral hernias: current state of the problem]. Khirurgiya. Zhurnal im. N.I. Pirogova - Surgery. Journal named
3. Postoperative incisional hernias-undecided problems / В. Г. Плешков, О. И. Агафонов // Journal of Experimental and Clinical Surgery. - 2009. - Vol. 2, No 3. - C. 248-255.

4. Оценка осложнений у больных с грыжами в зависимости от степени операционного риска и тяжести травмы / С. Ю. Пушкин [и др.] // Тольяттинский медицинский консилиум. - 2011. - № 3-4. - С. 154-157. after N.I. Pirogov, 76-80 [in Russian].

3. Peleshkov. V.H., \& Ahafonov, O.I. (2009). Postoperative incisional hernias-undecided problems. Journal of Experimental and Clinical Surgery, 2 (3), 248-255.

4. Pushkin, S.Yu. (2011). Otsenka oslozhneniy u bolnykh s gryzhami v zavisimosti ot stepeni operatsionogo riska i tyazhesti travmy [Assessment of complications in patients with hernias depending on the degree of operational risk and the severity of injury]. Tolyatinskiy med. kons. - Togliatti Medical Council, 3-4, 154-167 [in Russian].

Получено 02.06.2020

Электронный адресс для переписки: salimdavlatov@sammi.uz

\author{
S. S. DAVLATOV, B. A. MARDANOV
}

Samarkand State Medical Institute, Republic of Uzbekistan, Samarkand

\title{
VERIFICATION OF THE SYSTEMATIC APPROACH TO PERFORMING SIMULTANEOUS OPERATIONS ON THE ABDOMINAL ORGANS AND ABDOMINAL WALL IN PATIENTS WITH VENTRAL HERNIA
}

The aim of the work: to improve the quality of treatment of patients with ventral hernia by reducing the frequency and severity of complications after simultaneous and reconstructive surgery on the abdominal organs and abdominal wall.

Materials and Methods. The study included the results of treatment of 197 patients with simultaneous pathology of the abdominal cavity and abdominal wall, admitted to the Surgical Department of the Clinic No. 1 of the Samarkand State Medical Institute.

Results and Discussion. In 197 patients, normal gastrointestinal function remained after the operation, only 4 patients (3 and 1 patient in the study groups) had intestinal paresis, which was stopped by medication. Abdominal complications were observed in 10 (5.1 \%) patients. In the early postoperative period, abdominal complications after simultaneous operations can be divided into two: complications from the main stage of the operation and complications from the simultaneous stage of the operation. From the side of the main stage of the operation, 5 (2.5\%) patients ( 3 in the comparison group and 2 in the main group) had intestinal paresis after hernioalloplasty, and 1 $(0.5 \%)$ patient from the comparison group also had urinary retention after hernioalloplasty. In 2 (2.1\%) patients from the comparison group, the cause of intestinal paresis and urinary retention was increased intra-abdominal pressure.

The use of an improved modified scale for predicting perioperative complications made it possible to significantly improve the quality of preoperative preparation of patients with hepatitis $\mathrm{C}$ associated with simultaneous surgical diseases of the abdominal organs, to improve the patient's condition at an earlier date and, accordingly, reduce the frequency of postoperative outside abdominal complications from $10.7 \%$ to $2.8 \%$.

Key words: ventral hernia; abdominal cavity; simultaneous pathology; simultaneous operations; quality of life of patients. 
С. С. ДАВЛАТОВ, Б. А. МАРДАНОВ

Самаркандський державний медичний інститут, Республіка Узбекистан

\section{ВЕРИФІКАЦЯ СИСТЕМНОГО ПЦДХОДУ ВИКОНАННЯ СИМУЛЬТАННИХ ОПЕРАЦЙ НА ОРГАНАХ ЧЕРЕВНОӤ ПОРОЖНИНИ І ЧЕРЕВНІЙ СТІНЦ У ХВОРИХ 3 ВЕНТРАЛЬНОЮ ГРИЖЕЮ}

Мета роботи: поліпшення якості лікування хворих із вентральною грижею (ВГ) шляхом зниження частоти і тяжкості ускладнень після симультанних і реконструктивно-відновлювальних операцій на органах черевної порожнини і черевній стінці. Матеріали і методи. В основу дослідження включені результати лікування 197 хворих із симультанною патологією органів черевної порожнини і черевній стінці, що надійшли в хірургічне відділення 1-ї клініки Самаркандського державного медичного інституту.

Результати досліджень та їх обговорення. У 197 пацієнтів після операції зберігалася нормальна функція шлунково-кишкового тракту, лише у 4 хворих (3 і 1 пацієнта в групах дослідження) спостерігали парез кишечника, усунений медикаментозно. Абдомінальні ускладнення спостерігали в 10 (5,1%) хворих. У ранньому післяопераційному періоді абдомінальні ускладнення після симультанних операцій можна розділити на два: ускладнення з боку основного етапу операції та ускладнення з боку симультанного етапу операції. 3 боку основного етапу операції у 5 (2,5 \%) хворих (3 в групі порівняння і 2 в основній групі) після герніоалопластики спостерігали парез кишечника і 1 (0,5 \%) хворого з групи порівняння також після герніоалопластики спостерігали затримку сечі. У 2 (2,1 \%) хворих із групи порівняння причиною парезу кишечника і затримки сечі був підвищений внутрішньочеревний тиск

Використання удосконаленої модифікованої шкали прогнозування періопераційних ускладнень дозволило достовірно поліпшити якість передопераційної підготовки хворих із ВГ і супутніми симультанними хірургічними захворюваннями органів черевної порожнини, досягти поліпшення стану пацієнта в більш ранні терміни і відповідно скоротити частоту післяопераційних позаабдомінальних ускладнень з 10,7 до 2,8 \%.

Ключові слова: вентральна грижа; черевна порожнина; симультанна патологія; симультанні операції; якість життя хворих. 